\title{
A Numerical Model for Simulating the Indoor Climate inside the Growing Chambers of Vertical Farms with Case Studies
}

\author{
Shengbo Zhang and Ben Schulman
}

\begin{abstract}
Vertical indoor farming is a contemporary concept of growing plants. Indoor climate control for a vertical farm is critical since a failing in climate control may cause a low yield and low-quality product. This paper introduces a method using MATLAB and Simulink to model the climate conditions in the growing chamber of vertical farms. The model consists of an enthalpy $(H)$ integration and a moisture content $(m)$ integration. The climate conditions such as dry bulb temperature $\left(T_{\mathrm{wb}}\right)$ and relative humidity $(\varphi)$ are extrapolated based on the specific enthalpy $(h)$ and humidity ratio $(w)$. The model was verified based on the parameters and observations found in an existing indoor vertical farm. Several case studies have been performed using this model on a new farm design to analyze the responses in climate conditions under different scenarios. The results show that the temperature and relative humidity of the growing chamber are maintained at $24^{\circ} \mathrm{C}$ and $55 \%$ when the HVAC (Heating, ventilation, and air conditioning) units operate under normal conditions (case study A). Other case studies focus on the response in climate conditions under abnormal circumstances. For the new vertical farm design in particular, it is concluded that the sizing of the proposed HVAC unit produces moderate climate conditions for growing plants - optimal condition may be achieved if the humidity ratio is further lowered. It is recommended for any vertical farm to equip its growing chamber with extra capacity in cooling load for unexpected circumstances.
\end{abstract}

Index Terms-Climate control, HVAC, computer simulations.

\section{INTRODUCTION}

Vertical farming is a contemporary concept of growing plants in vertically stacked layers. Vertical farming deploys artificial light sources, climate conditioning, and automated fertigation for irrigation. In general, vertical farms can cultivate plants regardless of geographical location and local climate. When compared with a traditional greenhouse, a vertical farm allows more yield per square meter of land-use.

However, vertical farming requires rigorous climate control in the farm growing chamber, because ideal climate conditions not only ensure the quality of the plants but also the yield of the produce; plants grow better under optimal temperature, relative humidity, air flow, etc. Since climate control is primarily regulated by an HVAC (Heating,

Manuscript received June 23, 2017; revised August 24, 2017.

Shengbo Zhang is with the Department of Mechanical Engineering, Faculty of Engineering, Dalhousie University, 5248 Morris Street, PO Box 15000, Halifax, NS, B3H 4R2, Canada (email: Shengbo.zhang@dal.ca).

Ben Schulman is with TruLeaf Sustainable Agriculture, 540 Southgate Dr., Suite 204, Bedford, NS, B4A 0E1, Canada (email: bschulman@truleaf.ca). ventilation, and air conditioning) system, it is critical to verify the HVAC unit capacity to ensure the unit is capable of handling not only normal conditions but also unexpected circumstances, such as sudden cut-off in heat input from the lights and malfunction of a HVAC unit. Therefore, a one-dimensional model using MATLAB and Simulink was developed to study the interaction between the HVAC operation and indoor climate conditions in the growing chamber for a new farm design.

A similar study [1] focus on the energy modeling of indoor plant factories for analyzing energetic expenditure and performance of closed systems. Although this model included a wide range of transfer of energy, dynamics system response, the focus of this paper, could not be derived from such modeling.

\section{MODEL COMPONENTS}

\section{A. General}

The entire farm growing chamber is modeled as a control volume with one inlet and one outlet, as shown in Fig. 1.

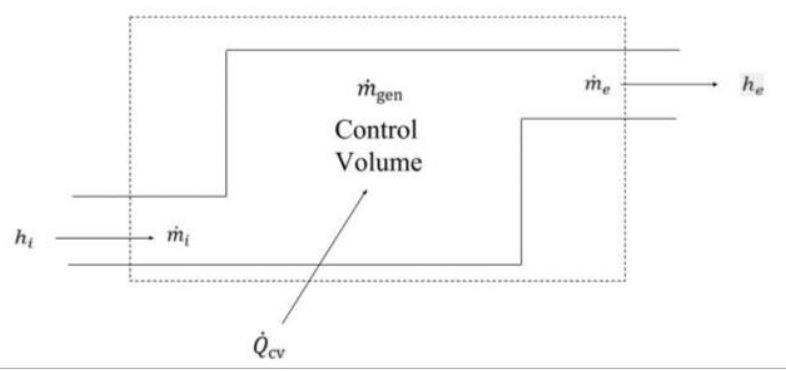

Fig. 1. Control volume analysis.

The inlet to the control volume represents the supply air (i.e. the air leaving the evaporator coils) from the HVAC unit whereas the outlet denotes the return air (i.e. the air entering the evaporator coils). The model assumes both the elevation and the velocity of the inlet and outlet are the same. This assumption may inevitably introduce some errors, which will be further discussed in the Discussions section. In addition, work applied to the control volume, by means of shaft work, is neglected, since no pump work or turbine work is present in the system. Therefore, the energy rate balance equation can be simplified as

$$
\begin{aligned}
\frac{d E_{\mathrm{CV}}}{d t}=\dot{Q}_{\mathrm{CV}} & -\dot{W} /_{\mathrm{CV}}+\dot{m}_{\mathrm{i}}\left(h_{\mathrm{i}}+\frac{V_{\mathrm{i}}^{2}}{\not 2}+g z_{\mathrm{i}}\right) \\
& -\dot{m}_{\mathrm{e}}\left(h_{\mathrm{e}}+\frac{V_{\mathrm{e}}^{2}}{\not 2}+g z_{\mathrm{e}}\right)
\end{aligned}
$$


where $Q \hat{\varepsilon}_{v}=$ the heat addition to the control volume in $\mathrm{J} / \mathrm{s}, \dot{m}_{\mathrm{i}}$ and $\dot{m}_{\mathrm{e}}=$ the mass flow rates of the moist air at the inlet and outlet of the control volume in $\mathrm{kg} / \mathrm{s}$, and $h_{\mathrm{i}}$ and $h_{\mathrm{e}}=$ the specific enthalpy of the air flow at inlet and outlet in $\mathrm{J} / \mathrm{kg}$.

$d E_{\mathrm{CV}} / d t$ is the rate of change in energy for a transient system, it follows

$$
d E=d U+d(\mathrm{KE})+d(\mathrm{PE})
$$

where $d(\mathrm{KE})=$ the change in kinetic energy in $\mathrm{J}, d(\mathrm{PE})=$ the change in potential energy in $\mathrm{J}$, and $d U=$ the change in internal energy in $\mathrm{J}$.

Again, the change in potential energy and potential energy can be neglected.

The enthalpy change for may be computed by

$$
d H=d U+p d V+V d p
$$

where $p d V=$ boundary work in $\mathrm{J}$ and $V d p=$ the shaft work applicable to devices such as turbines, compressors, and pumps in $\mathrm{J}$.

For this model, it can be assumed that the pressure and volume are both constant. Therefore,

$$
d E \approx d U \approx d H
$$

such that the final energy equation used for the modeling follows

$$
\frac{d H_{\mathrm{CV}}}{d t}=\dot{Q}_{\mathrm{CV}}+\dot{m}_{\mathrm{i}} h_{\mathrm{i}}-\dot{m}_{\mathrm{e}} h_{\mathrm{e}}
$$

In addition to the energy balance, the mass balance of the control volume follows

$$
\frac{d m_{\mathrm{cv}}}{d t}=\dot{m}_{\mathrm{i}}-\dot{m}_{\mathrm{e}}+\dot{m}_{\mathrm{gen}}
$$

where $d m_{\mathrm{cv}} / d t=$ the rate of change of mass within the control volume in $\mathrm{kg} / \mathrm{s}$ and $\dot{m}_{\text {gen }}=$ the mass generation within the control volume by the transpiration of the plants and the evaporation of the open surface water in $\mathrm{kg} / \mathrm{s}$.

As in the energy balance equation, the left-hand side of the equation is not zero since transient analysis is required.

\section{B. MATLAB Model}

Fig. 2 shows the Simulink diagram.

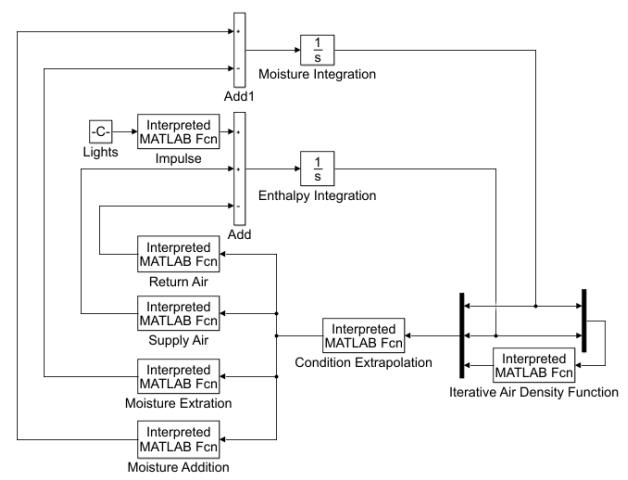

Fig. 2. Simulink model diagram.
The conservation of mass and conservation of energy dictate two integrators in this model - the enthalpy integration and moisture content integration. In addition, the model consists of six function evaluations at each timestep. The Iterative Air Density Function evaluates the density of the moist air based on the total moisture and total enthalpy. The dry air mass, calculated based on the initial conditions, is assumed to be invariable regardless of the climate conditions. Hence, the moisture content integration only integrates the mass of the moisture in the farm growing chamber. The Condition Extrapolation function extrapolates the dry bulb temperature and relative humidity based on a specific enthalpy and a humidity ratio. The functions Return Air and Supply Air calculate $\dot{m}_{\mathrm{e}} h_{\mathrm{e}}$ and $\dot{m}_{\mathrm{i}} h_{\mathrm{i}}$ on the right-hand side of the energy balance equation based on the sensible and latent heat cooling rates of the HVAC unit, derived from the climate conditions - dry bulb temperature and relative humidity. Meanwhile, the functions Moisture Extraction and Moisture Addition evaluate the rate at which the HVAC unit extracts the moisture and the rate of moisture addition by trans-evaporation. The energy input to the system, mainly contributed by the LED lights, is denoted as a constant input to the integrator.

\section{1) Density of moist air}

The Iterative Air Density Function solves the density of moist air based on the total enthalpy and total moisture in the control volume. The function takes an initial set of guesses of dry bulb temperature and air density to obtain the total mass of air for the subsequent calculations on the specific enthalpy of the air and the mass humidity ratio. Based on the specific enthalpy and the humidity ratio, psychometric function extrapolates other climate conditions including dry bulb temperature and relative humidity to obtain the next iteration of density. The function outputs the density if the difference between two guesses is within 0.0001 .

The density of moist air may be calculated by [2]

$$
\rho=\frac{p M_{\mathrm{a}}}{Z R T}\left[1-x_{\mathrm{V}}\left(1-\frac{M_{\mathrm{V}}}{M_{\mathrm{a}}}\right)\right]
$$

where $p=$ the total barometric pressure of moist air in $\mathrm{Pa}, M_{\mathrm{a}}$ $=$ the molar mass of dry air in $\mathrm{kg} / \mathrm{mol}, Z=$ the compressibility factor, $R=$ the molar gas constant in $\mathrm{J} / \mathrm{mol} / \mathrm{K}, T=$ the thermodynamics dry bulb air temperature in $\mathrm{K}, x_{\mathrm{V}}=$ the mole fraction of water vapor, and $M_{\mathrm{V}}=$ the molar mass of water in $\mathrm{kg} / \mathrm{mol}$.

The detailed calculation of the above parameters can be found in [2].

\section{2) Condition extrapolation}

The Condition Extrapolation function extrapolates the dry bulb temperature and the relative humidity.

The relationship between specific enthalpy, humidity ratio, and dry bulb temperature follows [3]

$$
h=1.006 T_{\mathrm{db}}+w\left(2501+1.86 T_{\mathrm{db}}\right)
$$

where $T_{\mathrm{db}}=$ dry bulb temperature in ${ }^{\circ} \mathrm{C}, w=$ the humidity ratio in $\mathrm{kg} / \mathrm{kg}$, and $h=$ the specific enthalpy in $\mathrm{J} / \mathrm{kg}$.

The relative humidity, defined as the ratio of the mole 
fraction of water vapor to the mole fraction of saturated air at the same temperature and pressure [3]. It can also be expressed as

$$
\varphi=\frac{p_{\mathrm{w}}}{p_{\mathrm{ws}}}
$$

where $p_{\mathrm{w}}=$ the partial pressure of water vapor in $\mathrm{Pa}, p_{\mathrm{ws}}=$ the saturation of water vapor in the absence of air at a given temperature in $\mathrm{Pa}$.

The correlation between the previously determined humidity ratio and the partial pressure of water vapor is given by [3]

$$
w=0.621945 \frac{p_{w}}{p-p_{w}}
$$

where $p=$ the total barometric pressure of moist air in Pa.

Derived from the Hyland-Wexler equations, saturation pressure varies with the dry bulb temperature as [3]

$$
\ln p_{w s}=\frac{C_{1}}{T}+C_{2}+C_{3} T+C_{4} T^{2}+C_{5} T^{3}+C_{6} \ln T
$$

where $C_{1}=-5.8002206 \times 10^{3}, C_{2}=1.3914993, C_{3}=$ $-4.8640239 \times 10^{-2}, \quad C_{4}=4.1764768 \times 10^{-5}, \quad C_{5}=$ $-1.4452093 \times 10^{-8}$, and $C_{6}=6.545967$.

\section{3) HVAC cooling capacity extrapolation}

The model analyzes the transient response of the system based on the HVAC unit cooling rate. The extrapolation of the HVAC performance is based on the real-time climate conditions - the dry bulb temperature, and relative humidity. Fig. 3 summarizes the variation of the total heat removal and sensible heat removal rate depending on various dry bulb temperatures entering the HVAC unit's evaporator coil, and Fig. 4 for different relative humidity. The HVAC unit is rated at 80-ton, and the proposed design consists of three such units.

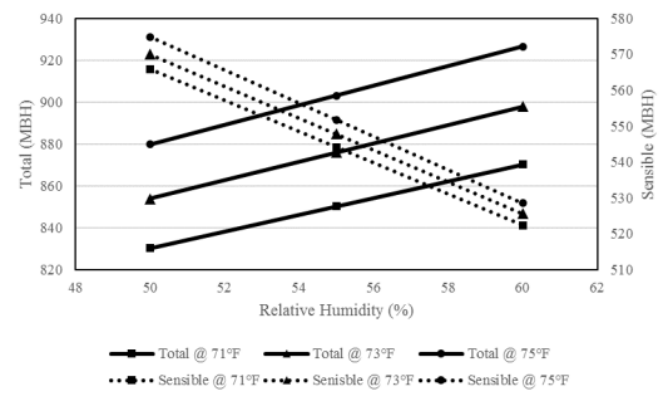

Fig. 3. HVAC unit ratings under different temperature.

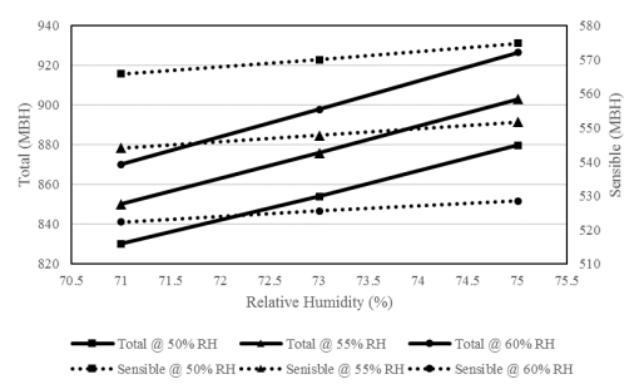

Fig. 4. HVAC unit ratings under different relative humidity.
Some general observations can be drawn from the above figures. First, at the same relative humidity, the unit rating on total heat removal, sensible heat removal, and latent heat removal rates increase with a rise in temperature. Second, at the same temperature level, the increase in relative humidity increases both total heat removal rate and latent heat removal rate, and decreases the sensible cooling load.

Typically, the HVAC unit manufacturer only provides specifications on the volumetric flow rate. It can be converted to the mass flow rate by

$$
\dot{m}=\rho \dot{V}
$$

where $\dot{V}=$ the volumetric flow rate of the air passing through the HVAC unit in $\mathrm{m}^{3} / \mathrm{s}$.

Since the HVAC unit performance correlates with two variables - dry bulb temperature and relative humidity, a surface fit by MATLAB fit function is used when extrapolating the unit performance. Since nine data points are present in this model, a polynomial surface fits with degree 2 in both $x$-domain and $y$-domain (the $x$-domain represents the temperature whereas the $y$-domain represents the relative humidity). Such surface fit equation follows

$$
\begin{aligned}
f(x, y)=C_{0,0} & +C_{1,0} x+C_{0,1} y+C_{2,0} x^{2} \\
& +C_{1,1} x y+C_{0,2} y^{2}
\end{aligned}
$$

where the $C$ values are the coefficients determined by the MATLAB fit function.

Based on the data shown in Fig. 3 and Fig. 4, Fig. 5 shows the surface fit for the total heat removal capacity for the HVAC unit mentioned above Fig. 6 shows the surface fit for the sensible heat cooling capacity.

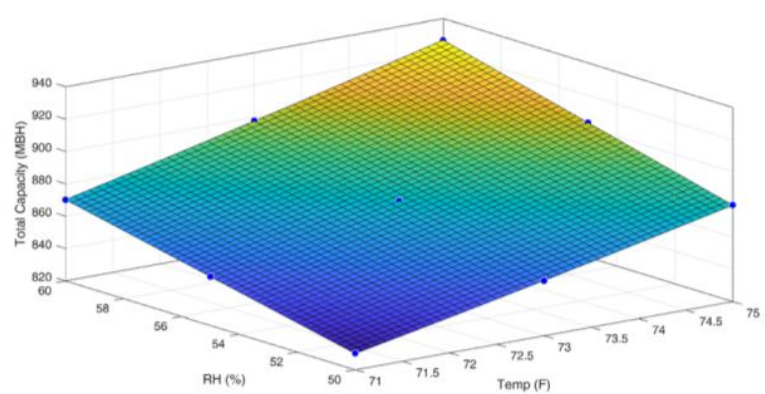

Fig. 5. Total capacity surface fit.

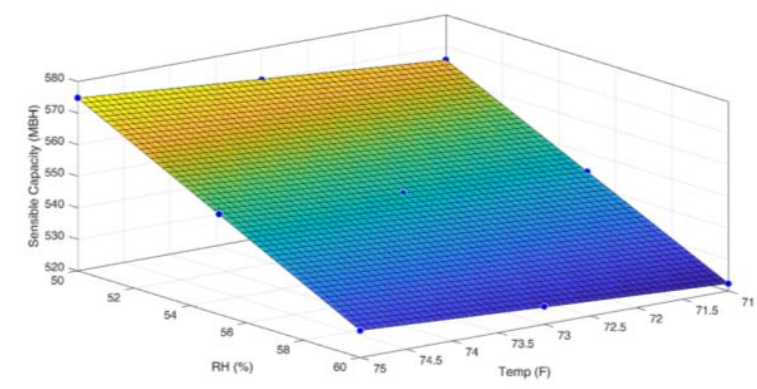

Fig. 6. Sensible capacity surface fit.

With the sensible heat removal rate, the function determines the air temperature after passing though the evaporator coils (or the air temperature at the supply side of the unit) by [4] 


$$
\dot{Q}_{\mathrm{s}}=\dot{m} c_{\mathrm{p}}\left(T_{1}-T_{2}\right)
$$

where $\dot{Q}_{\mathrm{s}}=$ the sensible heat removal rate in $\mathrm{J} / \mathrm{s}, c_{\mathrm{p}}=$ the specific heat of air constant $\left(1.01 \mathrm{~kJ} / \mathrm{kg}^{\circ} \mathrm{C}\right), T_{1}=$ the return air dry bulb temperature in ${ }^{\circ} \mathrm{C}, T_{2}=$ the supply air dry bulb temperature in ${ }^{\circ} \mathrm{C}$.

The change in humidity ratio can be calculated based on latent heat removal rate as [5]

$$
\dot{Q}_{1}=\dot{m} h_{\mathrm{fg}}\left(w_{1}-w_{2}\right)
$$

where $\dot{Q}_{\mathrm{I}}=$ the latent heat removal rate (the difference between the total cooling capacity and sensible cooling capacity) in $\mathrm{J} / \mathrm{s}, h_{\mathrm{fg}}=$ enthalpy representing the latent heat of water vapor at the dew point of the air entering the evaporator coil in $\mathrm{J} / \mathrm{kg}, w_{1}=$ the return air humidity ratio in $\mathrm{kg} / \mathrm{kg}$, and $w_{2}$ $=$ the supply air humidity ratio in $\mathrm{kg} / \mathrm{kg}$.

With the dry bulb temperature and the humidity ratio, the specific enthalpy of the supply air $\left(h_{\mathrm{i}}\right)$ can be subsequently determined by the temperature and the humidity ratio according to Eq. (8). The specific enthalpy of the HVAC return air, $h_{\mathrm{e}}$, is the same as the specific enthalpy of the air inside the farm growing chamber - the control volume, since the return side of the HVAC unit directly draws the air from farm growing chamber. Therefore, with these enthalpy values, the two terms on the right-hand side of the equation, $\dot{m}_{\mathrm{e}} h_{\mathrm{e}}$ and $\dot{m}_{\mathrm{i}} h_{\mathrm{i}}$, can be determined.

The amount of moisture extracted by the HVAC unit is based on the difference in humidity ratio. It may be calculated by [4]

$$
\dot{m}_{\mathrm{dm}}=\dot{m}\left(w_{2}-w_{1}\right)
$$

where $\dot{m}_{\mathrm{dm}}=$ the rate of moisture removal in $\mathrm{kg} / \mathrm{s}$.

\section{4) Moisture addition function}

The transpiration rate of the plants can be evaluated by the Penman-Monteith equation with FAO-56 by [6] as

$$
E T_{0}=\frac{0.408 \Delta\left(R_{\mathrm{n}}-G\right)+\gamma \frac{900}{T+273} u_{2}\left(e_{\mathrm{s}}-e_{\mathrm{a}}\right)}{\Delta+\gamma\left(1+0.34 u_{2}\right)}
$$

where $E T_{0}=$ reference evapotranspiration in $\mathrm{mm} / \mathrm{day}, R_{\mathrm{n}}=$ net radiation at the crop surface in $\mathrm{MJ} / \mathrm{m}^{2} /$ day, $G=$ soil heat flux density in $\mathrm{MJ} / \mathrm{m}^{2} /$ day, $T=$ mean daily air temperature at $2 \mathrm{~m}$ height in ${ }^{\circ} \mathrm{C}, u_{2}=$ wind speed at $2 \mathrm{~m}$ height in $\mathrm{m} / \mathrm{s}, e_{\mathrm{s}}=$ the saturation vapor pressure in $\mathrm{kPa}, e_{\mathrm{a}}=$ actual vapor pressure in $\mathrm{kPa}, e_{\mathrm{s}}-e_{\mathrm{a}}=$ saturation vapor pressure deficit in $\mathrm{kPa}, \Delta=$ slope vapor pressure curve in $\mathrm{kPa} /{ }^{\circ} \mathrm{C}$, and $\gamma=$ psychrometric constant in $\mathrm{kPa} /{ }^{\circ} \mathrm{C}$.

The above equation takes into account two factors that influence the transpiration of plants - radiation and wind. The net radiation, $R_{\mathrm{n}}$, is the difference between the incoming and outgoing radiation at the crop surface. This number is positive when radiation from lights is present and negative when there is no radiation.

The general equation for evaluating the irradiation of the surface over a unit area of broadcast follows [7]

$$
E=\int_{0}^{\infty} \int_{\phi_{1}}^{\phi_{2}} \int_{\theta_{1}}^{\theta_{2}} I_{\lambda, i}(\lambda, \theta, \phi) \cos \theta \sin \theta d \theta d \phi d \lambda
$$

where $I_{\lambda, i}(\lambda, \theta, \phi)=$ the spectral intensity of the body in $\mathrm{W} / \mathrm{m}^{2} / \mathrm{sr} / \mu \mathrm{m}$ and $E=$ emissive power in $\mathrm{W} / \mathrm{m}^{2}$.

However, this general equation only applies to the intercepting surface normal to the direction of radiation of the body of emission, which is a hypothetical, hemispherical surface centered at the body of emission. An additional cosine term must append to the integral for integrating the surface not normal to the direction of the radiation. While it is difficult to obtain the function of the spectral intensity of the grow lights, an alternative method is used to estimate the irradiation from the lights at the crop surface. Typically, the light manufacturer advertises the $P P F D$ value at the canopy at a certain distance from the lights. Therefore, the Planck-Einstein relation is used to approximate the surface irradiation from this value as

$$
E_{\mathrm{p}}=\frac{h c}{\lambda}
$$

where $E_{\mathrm{p}}=$ the energy of a photon in $\mathrm{J}, h=$ the Planck constant $\left(6.63 \times 10^{-34} \mathrm{~m}^{2} \cdot \mathrm{kg} / \mathrm{s}\right), c=$ the speed of light $\left(3 \times 10^{8}\right.$ $\mathrm{m} / \mathrm{s})$, and $\lambda=$ the light wavelength $(400 \mu \mathrm{m})$.

Therefore, the irradiation from the lights at the surface of the crop is

$$
E_{\mathrm{irr}}=\frac{A h c}{\lambda} \cdot P P F D \cdot 1 \times 10^{-6}
$$

where $E_{\mathrm{irr}}=$ the irradiation from the lights at the surface in $\mathrm{W} / \mathrm{m}^{2}$ and $A=$ the Avogadro's number $\left(6.022 \times 10^{23} \mathrm{~mol}^{-1}\right)$.

In addition to the transpiration from the plants, the moisture addition function calculates the evaporation rate from the water surface directly exposed to the air, which approximately accounts for $10 \%$ of the total grow area. Standards exist for indoor pools application in evaluating the evaporation rate, and the evaporation rate follows [5]

$$
w_{\mathrm{p}}=4 \times 10^{-5} A\left(p_{\mathrm{ws}}-p_{\mathrm{a}}\right) F_{\mathrm{a}}
$$

where $A=$ the area of the exposed water surface in $\mathrm{m}^{2}, p_{\mathrm{ws}}=$ the saturation vapor pressure at the surface water temperature (Eq. (11)) in $\mathrm{kPa}, p_{\mathrm{a}}=$ saturation pressure at room air dew point in $\mathrm{kPa}$, and $F_{\mathrm{a}}=$ the indoor pool activity factor ( 1 for indoor farm application for a high level of activities).

Parameter $p_{\mathrm{a}}$ may be determined based on temperature and relative humidity. Some typical values in $\mathrm{kPa}$ can be found in Table I from [8].

TABLE I: SATURATION PRESSURE AT AIR DEW POINT

\begin{tabular}{cccc}
\hline \hline Temperature $\left({ }^{\circ} \mathrm{C}\right)$ & $40 \% \mathrm{RH}$ & $50 \% \mathrm{RH}$ & $60 \% \mathrm{RH}$ \\
\hline 20 & 0.94 & 1.17 & 1.40 \\
25 & 1.27 & 1.58 & 1.90 \\
30 & 1.70 & 2.12 & 2.55 \\
\hline \hline
\end{tabular}

\section{5) Miscellaneous functions}

Heat input from lights, $\dot{Q}_{\mathrm{CV}}$ on the right-hand side of the energy balance equation, is defined as a constant input to the 
integrator. The Impulse function is implemented to investigate the system response under sudden cut-off of heat input from lights to mimic the scheduled daily light switch-off.

\section{MODEL VERIFICATION}

The model was verified prior to being applied to perform the case studies.

It has long been reported that the HVAC unit installed in the existing farm is under-performing so that the relative humidity level is always above $60 \%$, with occasional spikes to more than $90 \%$. Therefore, the parameters of the model have been adjusted according to the existing farm specifications to simulate the climate conditions and compare the results with the observations.

The simulation was carried out for a time span of three hours and the initial temperature and relative humidity were set to $30^{\circ} \mathrm{C}$ and $30 \%$ respectively. Fig. 7 demonstrates the temperature variation, and Fig. 8 shows the relative humidity level variation.

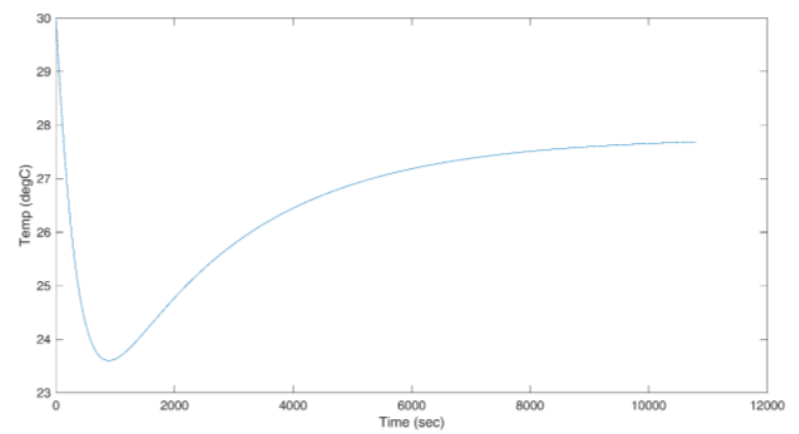

Fig. 7. Temperature response (existing farm).

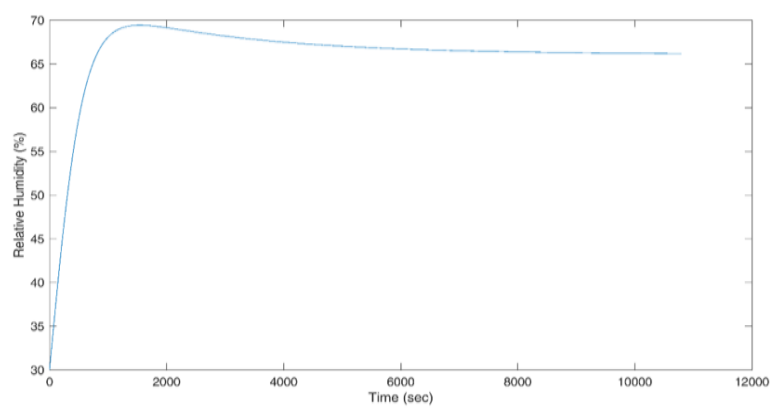

Fig. 8. Relative humidity response (existing farm).

It can be observed that the temperature approached $27.7^{\circ} \mathrm{C}$ and the relative humidity converged to $66 \%$. The simulation results agree mostly with the actual climate conditions in the existing farm. Therefore, the model is said to be validated, and it can be further implemented for simulating and evaluating the case studies based on the new farm.

\section{Results of CAse Studies}

This section outlines the simulation results of several case studies. Case A and Case B simulate the climate when the HVAC units operate under normal performance with a different set of initial condition. Case $\mathrm{C}$ simulates the climate with malfunctioning of one HVAC unit. Case D simulates the response in climate conditions when LED grow lights are turned off.

\section{A. Case A: HVAC Units under Normal Performance}

Fig. 9 shows the air temperature response under the HVAC unit's normal operation and Fig. 10 shows the humidity response. The initial temperature was defined as $30^{\circ} \mathrm{C}$ and the initial relative humidity as $80 \%$.

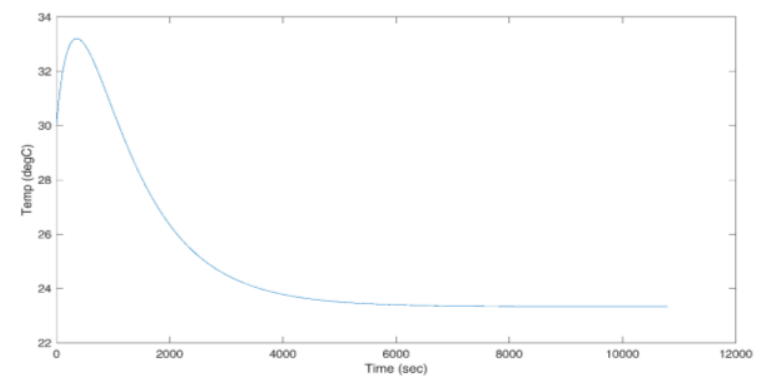

Fig. 9. Temperature response for of new farm with normal operation of the HVAC unit.

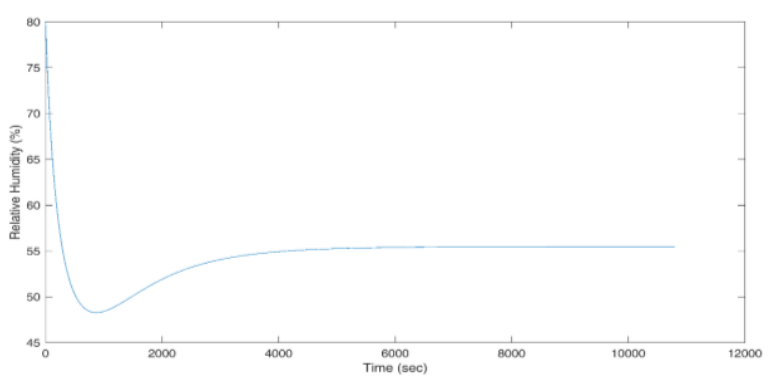

Fig. 10. Relative humidity response of the new farm with normal operation of the HVAC unit.

\section{B. Case B: Different Initial Condition}

Another study was conducted with a different initial relative humidity $(30 \%)$ instead of $80 \%$. Fig. 11 shows the temperature response whereas Fig. 12 shows the relative humidity response.

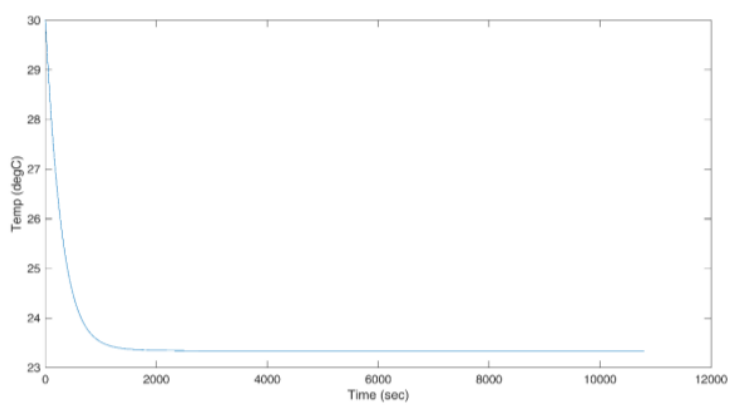

Fig. 11. Temperature response of the new farm with different initial condition.

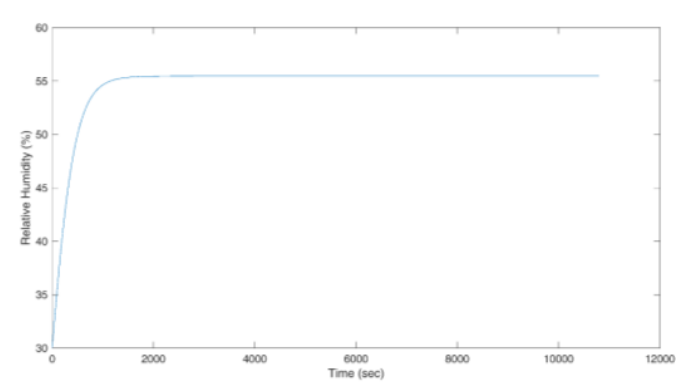

Fig. 12. Relative humidity response of the new farm with different initial condition. 


\section{Case C: Malfunctioning of One HVAC Unit}

It is also important to study the system behavior with a malfunction of one HVAC unit. Fig. 13 shows the temperature response and Fig. 14 shows the relative humidity response.

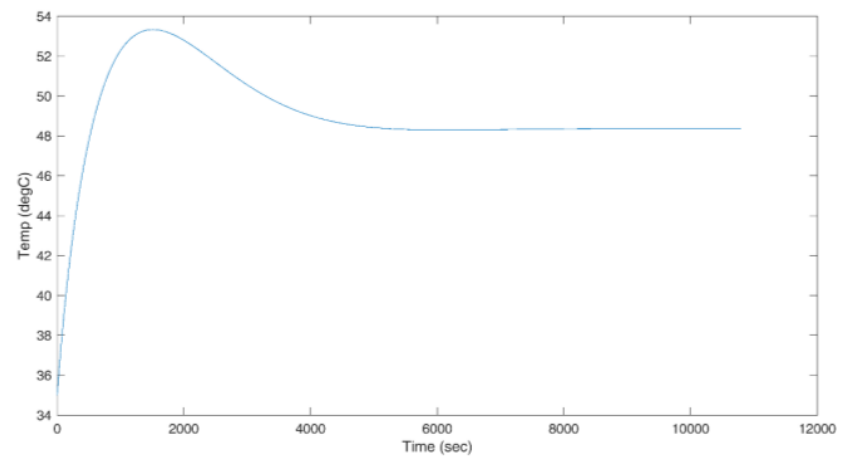

Fig. 13. Temperature response of the new farm with HVAC unit malfunctioning.

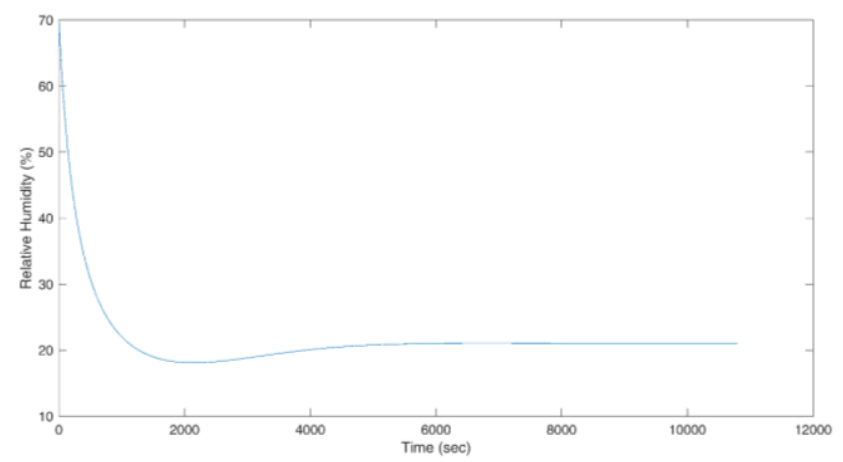

Fig. 14. Relative humidity response of the new farm with HVAC unit malfunctioning.

\section{Case D: LED Lights Switch-off}

A study on the response in climate conditions immediately after the lights were switched off was also performed. Note that this model does not implement the HVAC control system regulating the total heat removal rate and sensible heat removal rate, whereas the actual HVAC unit may have a sophisticated control system to adjust its performance in response to the sudden change in climate conditions caused by the loss in heat input. Therefore, the model only implements 100 seconds of loss in heat input from the lights just to demonstrate the consequences at an extreme circumstance (unregulated HVAC performance). Fig. 15 shows the temperature variation and Fig. 16 shows the relative humidity variation.

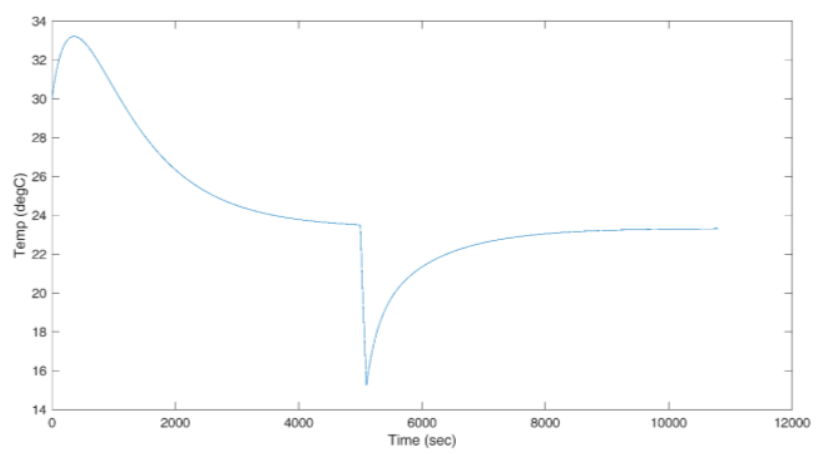

Fig. 15. Temperature response of the new farm with lights switch-off.

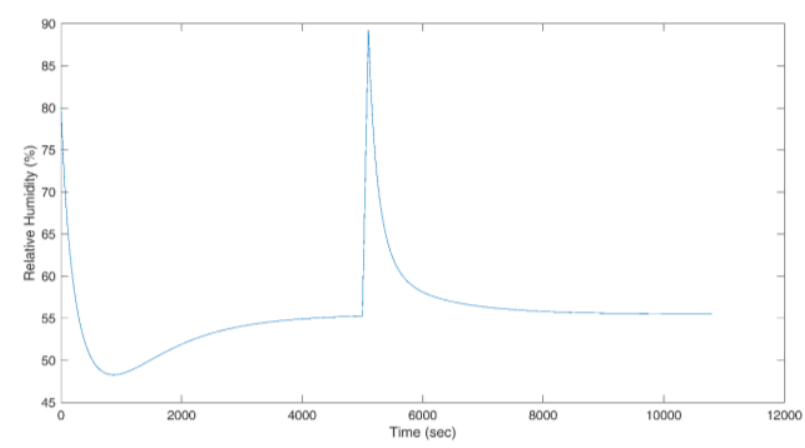

Fig. 16. Relative humidity response of the new farm with lights switch-off.

\section{DISCUSSION}

\section{A. Discussion on Results}

From Fig. 9 and Fig. 10 (Case A), when the HVAC unit operates under the designed capacity, the air temperature inside the farm growing chamber converged to $24^{\circ} \mathrm{C}$ whereas the relative humidity level was maintained at $55 \%$. As seen in [9], the increase in vapor pressure deficit - converted from the temperature and the relative humidity according to [10], may increase the transpiration rate for various plants. In this essence, at $24^{\circ} \mathrm{C}$ temperature and $55 \%$ relative humidity, the resulting vapor pressure deficit is $1.3 \mathrm{kPa}$, which is moderate for plant transpiration. Literature [11] deduced a positive linear relationship between the crop yield and transpiration rate, therefore, a moderate yield may be expected. At the same temperature level, the vapor pressure deficit may be further decreased if lowering the relative humidity.

The initial conditions do not influence the climate conditions at steady-state (Case B). The trans-evaporation rate and the heat input rate disguise the total and sensible cooling load, and desired climate conditions (temperature and relative humidity) shall match these cooling loads (or designed cooling capacities) when sizing the HVAC units. In addition, as previously mentioned, this model extrapolates the HVAC unit performance based on the air conditions entering the evaporator coils; the unit's cooling capacity increases with a rise in either temperature or relative humidity. Therefore, with the extra cooling capacity to eliminate the deficit, the climate conditions may always converge to the designed values.

One unit malfunctioning (Case C) will cause a detrimental impact on the climate conditions. From the above results, the air temperature upsurge to $50^{\circ} \mathrm{C}$ indicates that only two units in operation are not capable enough to combat the sensible heat input from the lights.

It can also be observed that the temperature and humidity changed drastically after the heat input from the lights is cut off (Case D). Even though the regulations on the performance of the HVAC is not implemented, as previously mentioned, a sudden drop in temperature may still be expected in a real circumstance. The humidity ratio does not vary significantly since the mass of moisture and dry air mass do not change with the decrease in temperature. Therefore, temperature decrease does not have a significant impact on the partial pressure of water vapor, pw, since it only correlates with the humidity ratio, $w$, according to Eqn. (10) The saturation vapor pressure, on the other hand, drops with 
air temperature according to Eqn. (11). Therefore, based on Eqn. (9), with the same humidity ratio and a lower temperature, the relative humidity will be higher.

\section{B. Discussion on the Model}

Several assumptions were made while developing this model. First, the model was developed based on 1D transient analysis. 1D model assumes uniform air conditions throughout the entire control volume - uniform air temperature, uniform humidity ratio, and uniform relative humidity. The responses to any sudden change in the input or output parameters, for instance, the sudden light input cut-off, would be instantly reflected. In a real scenario, any abrupt changes may not manifest immediately since it takes time for the air particles or other matters to diffuse evenly throughout the growing chamber. For instance, for the light cut-off analysis case specifically, it leaves abundant time for the HVAC unit to sense the decrease in temperature to regulate its performance to adapt to the new condition upon ceasing the heat input; since the upsurge in relative humidity is expected, the HVAC unit may lower the amount of air entering the evaporator coils to maintain, or even reduce, the relative humidity due to the reduction in fin temperature for more moisture removal according to [12]. To demonstrate further, a 2D CFD (computational fluid dynamics) simulation was performed to analyze the air circulation for part of the growing chamber with the proposed growing rack system and ductwork design. In brief, the CFD software numerically solved the Navier-Stokes equation for compressible laminar flow as [13]

$$
\begin{aligned}
\rho\left(\frac{\partial \mathbf{u}}{\partial t}+\mathbf{u} \cdot \nabla \mathbf{u}\right) & =-\nabla p+\nabla \cdot\left(\mu\left(\nabla \mathbf{u}+(\nabla \mathbf{u})^{T}\right)-\frac{2}{3} \mu(\nabla \cdot \mathbf{u}) \mathbf{I}\right) \\
& +F
\end{aligned}
$$

where $\rho(\partial \mathbf{u} / \partial t+\mathbf{u} \cdot \nabla \mathbf{u})=$ inertial force in $\mathbf{N},-\nabla p=$ pressure force in $\mathrm{N}, \nabla \cdot\left(\mu\left(\nabla \mathbf{u}+(\nabla \mathbf{u})^{T}\right)-2 / 3 \mu(\nabla \cdot \mathbf{u}) \mathbf{I}\right)=$ viscous forces in $\mathrm{N}$, and $F=$ external force in $\mathrm{N}$.

When ignoring the viscous heating and pressure work, the governing equation for heat transfer follows [12]

$$
\rho C_{p} \frac{\partial T}{\partial t}+\rho C_{p} \mathbf{u} \cdot \nabla T=\nabla \cdot(k \nabla T)+Q
$$

where $\rho C_{p} \partial T / \partial t=$ Transient heat transfer in $\mathrm{J} / \mathrm{s}, \rho C_{p} \mathbf{u} \cdot \nabla T=$ heat transfer due to translation motion of molecules in $\mathrm{J} / \mathrm{s}, \nabla \cdot(k \nabla T)$ $=$ heat conduction in $\mathrm{J} / \mathrm{s}$, and $Q=$ heat source input in $\mathrm{J} / \mathrm{s}$.

Fig. 17 shows the air circulation around the part of the chamber.

The 2D CFD simulation modeled the cross section of the growing chamber. The model considered the placement of the growing racks and ductwork. From the above results, it can be observed that most of the air flow distributes in between the growing racks and circulates along the floor the space between two racking tiers, the location where the plants are, do not experience much air flow. In order to improve the uniformity of the air flow across the plants' canopy, literature [14] studies several arrangement and design of perforated air tube. Literature [15] experimentally studied two cases for controlling air flow devices to minimize the temperature of upper and lower beds and to promote crop growth. Since this paper mainly focuses on the MATLAB model for evaluating the HVAC performance, the detail for the CFD model is not discussed further.

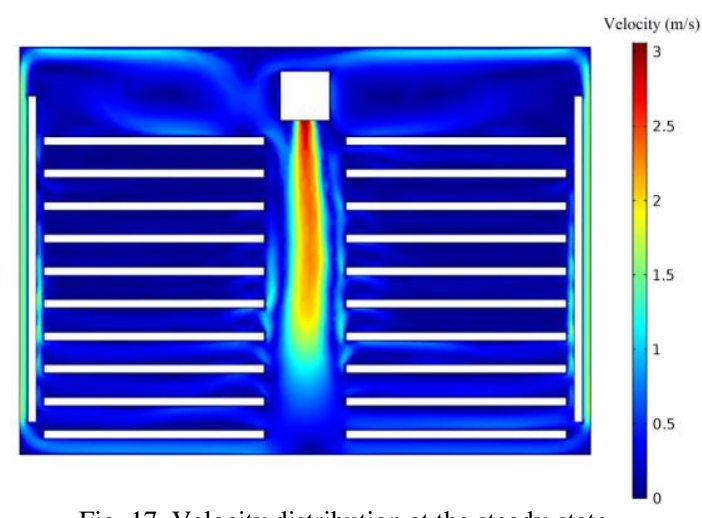

Fig. 17. Velocity distribution at the steady-state.

The one-dimensional analysis is justified for this application, since the goal is to approximate the HVAC unit performance instead of replicating the actual chamber. On the other hand, the benefit for the one-dimensional model is that it quickly reaches steady-state and allows for quicker convergence.

Second, the model assumes the inlet air flow and the outlet air flow have the same kinetic energy (K.E.) and potential energy (P.E.). This assumption is reasonable since the change in kinetic energy and potential energy are insignificant compared to the change in enthalpy. This was omitted because adding an extra layer of calculation inevitably makes the model more computationally expensive.

Third, the model assumes no additional heat input or heat loss other than from the LED lights. The farm growing chamber is enclosed in a large facility, and all the chamber walls are insulated. Therefore, the heat gain or heat loss though the walls are negligible. Additionally, air reheat capacity of HVAC unit was not given in the specification sheet. Therefore, the additional heat input from the air reheat coil was not considered.

Fourth, one of the design criteria is to introduce fresh air to the system and at the same time maintain the positive pressure to avoid air cross-contamination. This model, however, assumes the dry air mass is constant and the moisture content in the air variation is solely due to the trans-evaporation and moisture extraction through the HVAC unit. However, the outdoor air conditions vary mostly with the outdoor climate, and only a small portion of the air is drawn from outdoors. Therefore, it can be assumed that air exchange between outdoor and indoor is neglected.

\section{RECOMMENDATIONS}

\section{A. Recommendations on Modeling}

As discussed, the 1D model is not an ideal solution for evaluating the actual air condition surrounding the plants; some zones experience better air flow whereas others do not, so the actual climate in proximity to the plants may differ from the surroundings. A 3D model with the implementation of both air temperature and relative humidity is desired for studying the air conditions. This can be done by applying the 
Psychometric function into the CFD modeling, but this feature may add extensively to the computational effort and more computational time will be required.

Also, to improve the accuracy of the model, it is crucial to consider that the temperature of the outdoor air entering the condenser has an impact on the unit performance. Typically, the colder the outdoor temperature is, the better the unit performs in cooling and dehumidifying.

\section{B. Recommendations on Case Studies}

The result from the MATLAB and Simulink solutions show that the proposed unit is just enough to keep the desired air conditions, with $55 \%$ relative humidity and $22.5^{\circ} \mathrm{C}$ dry bulb temperature. Any unexpected change, such as the malfunction of one unit would cause a detrimental impact on the indoor climate. It is recommended for any vertical farm to equip its growing chamber with HVAC units with redundancy for abnormalities.

In the absence of literatures investigating how climate conditions have an impact on plant growth, in particular on leafy greens, it is recommended that further comprehensive research shall be performed to make more definite conclusions on the optimal climate conditions in the future.

\section{CONCLUSIONS}

For an indoor vertical farm, a failing in climate control impacts the quality and yield of produce. A MATLAB with Simulink model was built to simulate the climate conditions in the growing chamber. Prior to conducing the simulation on the company's new farm, the model was validated based on the parameters and observations on the company's existing farm.

For the investigated new farm design, the results of case studies demonstrated that the proposed sizing of the HVAC unit is capable of delivering moderate climate conditions to the growing chamber, thus moderate plant growth. However, the malfunction of one HVAC unit may cause an unfavorable effect on the climate - if keeping the same amount of heat input from the lights, the chamber temperature may upsurge to $50^{\circ} \mathrm{C}$. The model also predicted the variations in conditions during the light cut-off - the descent in temperature and the ascent in relative humidity. In a real circumstance, the changes in conditions may not be as rapid as the simulation predicted, and the HVAC units may have advanced control to self-adjust the performance to respond to the change in conditions.

A simulation based on a 3D model is recommended since the 1D model may only be used when evaluating the HAVC performance. The actual climate in proximity to the plants may differ from the surroundings. In addition, it is also important to consider the outdoor climate since the outdoor air entering the condenser may impact the performance of the HVAC unit.

HVAC units with higher cooling loads than required is recommended to create better growing conditions and prepare for unexpected unit's malfunction. In addition, more comprehensive research on the optimal growing conditions for leafy greens shall be conducted in the future.

\section{ACKNOWLEDGMENT}

We thank TruLeaf Sustainable Agriculture for providing the basis and critical data for this article. Shengbo Zhang also thanks the government of Nova Scotia for providing the Cooperative Education Incentive (CO-OP) program funding.

\section{REFERENCES}

[1] L. Graamans, A. Dobbelsteen, E. Meinen, and C. Stanghellini, "Plant factories; crop transpiration and energy balance," Agric. Syst., vol. 153, pp. 138-147, May 2017.

[2] R. S. Davis, "Equation for the determination of the density of moist air (1981/91)," Metrologia, vol. 29, no. 1, p. 67, 1992.

[3] American Society of Heating, 2013 ASHRAE Handbook: Fundamentals, SI edition.. Atlanta, GA: ASHRAE, 2013.

[4] R. H. Howell, "Principles of heating, ventilating, and air conditioning: a textbook with design data based on the 2005 ASHRAE Handbook-Fundamentals," Atlanta, Ga.: American Society of Heating, Refrigerating and Air-Conditioning Engineers, 2005.

[5] American Society of Heating, 2011 ASHRAE Handbook Heating, Ventilating, and air-Conditioning Applications, SI ed., Atlanta, Ga.: ASHRAE, 2011.

[6] R. G. Allen and Food and Agriculture Organization of the United Nations, Crop Evapotranspiration: Guidelines for Computing Crop Water Requirements, Rome: Food and Agriculture Organization of the United Nations, 1998.

[7] F. P. Incropera, Fundamentals of Heat and Mass Transfer, 7th ed., Hoboken, NJ: John Wiley, 2011.

[8] J. W. Lund, "Design considerations for pools and spas (natatoriums)," Oregon Renewable Energy Center - Geo-Heat Center, Sep. 2000.

[9] H. M. Rawson, J. E. Begg, and R. G. Woodward, "The effect of atmospheric humidity on photosynthesis, transpiration and water use efficiency of leaves of several plant species," Planta, vol. 134, no. 1, pp. 5-10, Jan. 1977.

[10] Barrett Bellamy Climate - Planck emission. [Online]. Available: http://www.barrettbellamyclimate.com/page18.htm

[11] C. T. Wit, "Transpiration and crop yields," p. 88, 1958.

[12] M. A. Andrade and C. W. Bullard, "Controlling Indoor Humidity Using Variable-Speed Compressors and Blowers," Air Conditioning and Refrigeration Center, College of Engineering, University of Illinois at Urbana-Champaign., Jul. 1999.

[13] COMSOL, “COMSOL multiphysics user's guide,” May 2012.

[14] Y. Zhang, M. Kacira, and L. An, "A CFD study on improving air flow uniformity in indoor plant factory system," Biosyst. Eng., vol. 147, pp. 193-205, Jul. 2016.

[15] T.-G. Lim and Y. H. Kim, "Analysis of airflow pattern in plant factory with different inlet and outlet locations using computational fluid dynamics," J. Biosyst. Eng., vol. 39, no. 4, pp. 310-317, 2014.

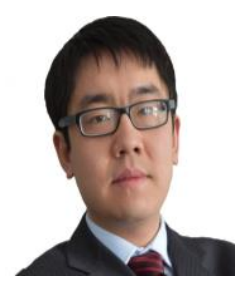

Shengbo Zhang is currently pursuing his B.Eng. in mechanical engineering degree at Dalhousie University, Halifax, Nova Scotia, Canada. He is currently working as a co-operative student at TruLeaf Sustainable Agriculture as an Engineering Specialist in Truro, Nova Scotia, Canada. He previously worked for an energy laboratory at Dalhousie University as a research assistant. His research interests include thermo-fluid dynamics, energy, and control systems.

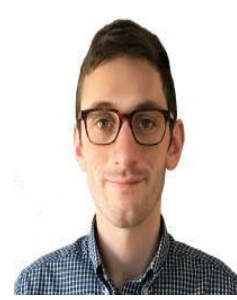

Ben Schulman was born in Prince Edward Island, Canada. He is a project engineer working for Truleaf Sustainable Agriculture. Graduating with with distinction from the Industrial Engineering program at Dalhousie University in 2016. Ben's role at Truleaf is expands beyond a single title. He has been working on developing and deploying more efficient, scalable, and automated production systems as Truleaf expands across Canada. 